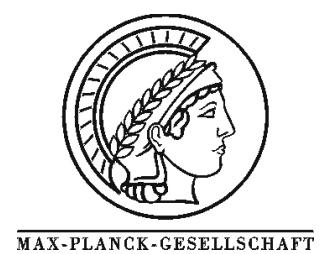

Journal of Catalysis 224 (2004) 1, 124-137

\title{
Incorporation of Manganese and Iron into the Zirconia Lattice in Promoted Sulfated Zirconia Catalysts
}

\author{
F.C. Jentoft, ${ }^{1 *}$, A. Hahn, ${ }^{1}$ J. Kröhnert, ${ }^{1}$ G. Lorenz, ${ }^{1}$ R.E. Jentoft, ${ }^{1}$ \\ T. Ressler, ${ }^{1}$ U. Wild, ${ }^{1}$ R. Schlögl ${ }^{1}$, C. Häßner, ${ }^{2}$ and K. Köhler ${ }^{2}$
}

${ }^{1}$ Department of Inorganic Chemistry, Fritz-Haber-Institute of the MPG, Faradayweg 4-6, 14195 Berlin, Germany
${ }^{2}$ Anorganisch-Chemisches Institut, Technische Universität München, Lichtenbergstr. 4, 85747 Garching, Germany

${ }^{*}$ Corresponding author: e-mail jentoft@fhi-berlin.mpg.de, phone +49 308413 4408, fax +493084134401

Received 23 September 2003; accepted 05 February 2004

\begin{abstract}
Two series of Mn- or Fe-promoted zirconia samples were prepared, (i) a series of sulfated-free reference compounds via co-precipitation of aqueous solutions containing zirconium and the promoter cation, and (ii) a series of catalysts via incipient-wetness impregnation of a sulfated zirconium hydroxide. The promoter content was varied between 0 and $5 \mathrm{wt} \%$ metal. All promoter-containing materials were calcined at $923 \mathrm{~K}$. The reference materials contained mainly isolated $\mathrm{Mn}$ or Fe species incorporated into the zirconia lattice as evidenced by stabilization of the tetragonal zirconia phase, EPR (isolated ions in highly symmetric environment), and a shrinking unit cell volume (XRD) of the tetragonal zirconia phase with increasing promoter content. Only the Mn-promoted catalysts showed such shrinkage in unit cell volume with increasing promoter content. At $2 \mathrm{wt} \%$ promoter content, Fe could, and Mn could not be detected by ion scattering spectroscopy on the surface of the catalysts. The Fepromoted catalysts contained $\mathrm{Fe}_{2} \mathrm{O}_{3}$-like surface species (EPR, XANES), which could at least in part be removed by washing with oxalic acid. Catalysts were tested for isomerization at $338 \mathrm{~K}$ using $1 \mathrm{kPa} n$-butane in balance of $\mathrm{N}_{2}$. At $0.5 \mathrm{wt} \%$ promoter content the maximum rates produced by the $0.5 \mathrm{wt} \%$ Mn-promoted and Fe-promoted sulfated zirconia were about 80 and $20 \mu \mathrm{mol} \mathrm{g}^{-1} \mathrm{~h}^{-1}$, respectively. Mn was thus more effective as a promoter for $n$-butane isomerization than $\mathrm{Fe}$, despite the more extensive incorporation into the zirconia lattice.
\end{abstract}

Keywords: Sulfated zirconia; iron; manganese; incorporation; solid solution; XRD; XANES; EPR, ISS; butane isom erization

\section{Introduction}

The activity of sulfated zirconia for skeletal isomerization of alkanes can be increased by addition of first row transition metal cations. Hsu et al. first presented a catalyst containing $1.5 \mathrm{wt} \% \mathrm{Fe}$ and $0.5 \mathrm{wt} \% \mathrm{Mn},{ }^{1}$ and this combination has been studied in detail ${ }^{2-28}$ because of a possible synergy effect between the two promoters. However, there is a controversy as to which individual cations are promoters and which are not. Arata $^{29}$ found $\mathrm{Mn}$ and $\mathrm{Fe}$ to have a positive, and $\mathrm{Cr}, \mathrm{Co}$, and $\mathrm{Ni}$ to have a negative effect for $n$-butane isomerization. Yori and Parera ${ }^{30}$ ranked $\mathrm{Ni}>\mathrm{Co}>\mathrm{Fe}$; $\mathrm{Cr}$ was also a promoter while $\mathrm{Cu}$ was an inhibitor. Ni has been claimed to be equally as good as the combination of $\mathrm{Mn}$ and $\mathrm{Fe}^{24}$ Coelho et al. ${ }^{24}$ and García et al. ${ }^{28}$ reported that $\mathrm{Mn}$ alone is without effect, Srinivasan et al. ${ }^{17}$ inferred Fe to be better than Mn. Some promoted sulfated zirconia catalysts deactivate rapidly, and the maximum activity may be missed under conditions of high conversion. Analyzing suitable reaction profiles, Lange et al. $^{31}$ found the following trend in the maximum rates for $n$-butane isomerization: $\mathrm{Mn}>\mathrm{Fe}>>\mathrm{Co}$ $>>\mathrm{Ni}>\mathrm{Zn}$, i.e. the promoting effect decreased from left to right in the periodic table. All promoted catalysts are similarly selective and predominantly produce isobutane, with propane and pentanes as side products. The first row transition metal promoters have thus qualitatively the same effect, which suggests a common yet unknown mode of operation. The promoting effect of $\mathrm{Mn}$ and $\mathrm{Fe}$ (and others) on sulfated zirconia has been ascribed to (i) increase of acid 
strength, ${ }^{10,20}$ some of these experiments were later proven misleading; ${ }^{11,15,16}$ (ii) facilitated formation and stabilization of carbenium ion and alkene intermediates on the surface, ${ }^{12,13}$ increased dehydrogenation ability, ${ }^{7,30}$ strengthened interaction with carbenium ions, ${ }^{32}$ stabilization of the transition state complex on the surface, ${ }^{7}$ (iii) a redox trigger of the acid catalyzed process, ${ }^{2}$ a different degree of synergism between redox and acid sites, ${ }^{22}$ a combination of a redoxactive metal site and an acid site in close proximity with oxidative dehydrogenation as initiating step, ${ }^{25}$ and (iv) formation of 'less oxidized' Zr species. ${ }^{33}$ Many of these suppositions point towards an interplay between redox and acidic sites, but no clear-cut picture has evolved, and the evidence for the promoter action is mainly indirect.

Attempts have been made to characterize the promoter species in iron and/or manganese promoted sulfated zirconia. Srinivasan et al., ${ }^{17}$ Hino and Arata, ${ }^{34}$ and Tábora and Davis ${ }^{3}$ concluded that $\mathrm{Fe}$ was present as (small clusters or rafts of) $\mathrm{Fe}_{2} \mathrm{O}_{3}$, and it was stated ${ }^{3}$ that there is no isomorphous substitution of $\mathrm{Fe}$ into tetragonal zirconia. According to Tanaka et al. ${ }^{4}$ and Yamamoto et al., ${ }^{5} \mathrm{Fe}^{3+}$ formed an interstitial-type solid solution with $\mathrm{ZrO}_{2}$. Miao et al. ${ }^{19}$ suspected that promoters may be present in the form of oxide solid solutions or highly dispersed on the surface. Scheithauer et al. ${ }^{23}$ and Millet et al. ${ }^{35}$ reported more than one species, i.e. (isolated) $\mathrm{Fe}^{3+}$ species besides (nanometer-sized) $\mathrm{Fe}_{2} \mathrm{O}_{3}$. Srinivasan et al. ${ }^{17}$ assumed a manganese oxide phase, Tanaka et al. ${ }^{4}$ and Yamamoto et al. ${ }^{5}$ detected $\mathrm{MnSO}_{4}$ in sulfate-containing and $\mathrm{Mn}_{2} \mathrm{O}_{3}$ in sulfate-free samples. Scheithauer et al. ${ }^{23}$ reported well-dispersed $\mathrm{Mn} 2+$. Jentoft et al. ${ }^{18}$ identified an average Mn oxidation state of +3 in the absence of sulfate and of about +2.7 in the presence of sulfate, indicating mixed valences for this element. Coelho et al. ${ }^{24}$ and García et al. ${ }^{36}$ suggested that Mn helps disperse Fe. In summary, the location and the state of the promoters is thus still a matter of debate.

Solid solutions are well known in the sulfate-free systems $\mathrm{Mn}-\mathrm{Zr}-\mathrm{O}$ and $\mathrm{Fe}-\mathrm{Zr}-\mathrm{O}$. Early systematic investigations were published by Stöcker, ${ }^{37,38}$ who prepared his solid solutions by rapid co-precipitation from a solution containing cations of $\mathrm{Zr}$ and, e.g., $\mathrm{Mn}, \mathrm{Fe}$, or $\mathrm{Ni}$, and subsequent heating in reducing or oxidizing atmosphere, typically at 873-1023 K. Mixing of $\mathrm{Zr}$ and $\mathrm{Mn}^{39-44}$ or $\mathrm{Fe}^{45}$ in the solution stage has yielded solid solutions in many cases. Impregnation of $\mathrm{ZrO}_{2}$ with metal cation solutions followed by calcination produced supported $\alpha-\mathrm{Fe}_{2} \mathrm{O}_{3}{ }^{46-49}$ with sometimes additional highly dispersed $\mathrm{Fe}^{3+}$ species present, ${ }^{48,49}$ or, accordingly supported $\alpha-\mathrm{Mn}_{2} \mathrm{O}_{3} \cdot{ }^{50}$ Solid solutions may also form through solid state reaction between e.g. $\mathrm{ZrO}_{2}$ and $\mathrm{MnO}$ at $1823 \mathrm{~K}$ in $\mathrm{N}_{2} .{ }^{51}$ Characteristic of these solid solutions is their structure. While the monoclinic phase is the thermodynamically stable structure for pure zirconia at room temperature, the tetragonal or the cubic zirconia phase, which are the high temperature polymorphs of $\mathrm{ZrO}_{2}$, are stabilized also at room temperature through the incorporation of $\mathrm{Fe}$ or $\mathrm{Mn}$.

Whether such incorporation also occurs in the promoted sulfated zirconia catalysts that are not co-precipitated but prepared by the incipient wetness method and calcined at moderate temperatures (823-973 K) has not been clarified. The phase stabilization effect would be obscured for sulfated systems because the presence of sulfate during calcination leads to an increased fraction of tetragonal material in the final product ${ }^{52,53}$ in comparison to pure zirconia. Interesting is the question of whether promoter species in the zirconia lattice and the resulting changes to the lattice are relevant for the catalytic performance.

The goal of this paper is to investigate the nature and location of the two most promising promoters of sulfated zirconia. Catalysts with different $\mathrm{Mn}$ or Fe content were prepared by the incipient wetness method, and a set of sulfate-free reference compounds was prepared by the co-precipitation method in order to achieve incorporation of $\mathrm{Mn}$ and $\mathrm{Fe}$ into the zirconia lattice. Experiments were conducted to dissolve surface species of both catalysts and reference compounds. Surface and bulk techniques, specifically ion scattering spectroscopy (ISS), X-ray diffraction (XRD), X-ray absorption spectroscopy (XAS), and electron paramagnetic resonance (EPR) were applied.

\section{Experimental}

\section{Preparation of catalysts}

Zirconium hydroxide materials were provided by MEL Chemicals (XZO 632/03 and XZO 682/01), either sulfatefree or doped with an amount of ammonium sulfate corresponding to 5-6 $\mathrm{wt} \% \mathrm{SO}_{3}$ (manufacturer's information, $\mathrm{SO}_{3}$ content on the $\mathrm{ZrO}_{2}$ content of $70-80 \%$ ). For all preparations, ${ }^{54}$ the precursors were dried for $21 \mathrm{~h}$ at $383 \mathrm{~K}$ and cooled in a desiccator. The promoter concentration was varied by varying the concentration of the $\mathrm{Mn}\left(\mathrm{NO}_{3}\right)_{2} * 4 \mathrm{H}_{2} \mathrm{O}$ or $\mathrm{Fe}\left(\mathrm{NO}_{3}\right)_{3} * 9 \mathrm{H}_{2} \mathrm{O}$ (both Merck, p.a.) solutions. The amount of promoter added corresponded to nominal concentrations of 0.5 to $5.0 \mathrm{wt} \%$ metal in the final catalysts. The amount of liquid added was $4 \mathrm{ml}$ per $10.9 \mathrm{~g}$ dried precursor and only portions of this amount were used in the promoter addition step. The nitrate solutions were added drop-wise under vigorous stirring in a porcelain mortar, the solution was added within $20 \mathrm{~min}$ and then the mixture was stirred for an additional $5 \mathrm{~min}$. The materials were dried at room temperature and calcined in quartz boats placed in a $29 \mathrm{~mm}$ i.d. quartz tube, which was purged with a $200 \mathrm{ml} \mathrm{m^{-1 }}$ flow of synthetic air. The heating rate was $3 \mathrm{~K} \mathrm{~min}^{-1}$ and unpromoted sulfated zirconia was treated $3 \mathrm{~h}$ at $823 \mathrm{~K}$ or $923 \mathrm{~K}$, promoted sulfated zirconia $3 \mathrm{~h}$ at $923 \mathrm{~K}$. Incipient-wetness prepared samples are denoted as $\mathrm{xFeSZ} \underline{\mathrm{i}}$ and $\mathrm{xMnSZ} \underline{\mathrm{i}}$ with $\mathrm{x}$ being the promoter content.

\section{Preparation of reference compounds}

$\mathrm{ZrO}\left(\mathrm{NO}_{3}\right)_{2} * 2 \mathrm{H}_{2} \mathrm{O}$ (Aldrich) and either $\mathrm{Mn}\left(\mathrm{NO}_{3}\right)_{2} * 4 \mathrm{H}_{2} \mathrm{O}$ or $\mathrm{Fe}\left(\mathrm{NO}_{3}\right)_{3} * 9 \mathrm{H}_{2} \mathrm{O}$ (both Merck, p.a.) were dissolved in about $100 \mathrm{ml}$ of distilled water in amounts corresponding to the desired stoichiometry. Rapid addition of a $25 \%$ aqueous solution of ammonia led to precipitation; as much of the ammonia solution was added as was necessary to reach $\mathrm{pH} \approx$ 9. The precipitate was filtered by vacuum, washed several times with a $10 \%$ ammonia solution, and dried for about 24 $\mathrm{h}$ at $383 \mathrm{~K}$. Calcination was performed in a $200 \mathrm{ml} \mathrm{min}^{-1}$ 
stream of synthetic air; $3 \mathrm{~g}$ of sample were heated in a quartz boat at $3 \mathrm{~K} \mathrm{~min}^{-1}$ to $923 \mathrm{~K}$ and were held at this temperature for $3 \mathrm{~h}$. The compositions of the samples were determined by AAS after digesting the samples in HF in an autoclave. Coprecipitated samples are denoted as $\mathrm{xMnZ} \underline{\mathrm{c}}$ and $\mathrm{xFeZ} \underline{\mathrm{c}}$, with $\mathrm{x}$ being the promoter content.

\section{Washing procedures for manganese-zirconia reference samples}

For the washing procedures with EDTA $(\mathrm{HCl})$ solutions 0.2 $\mathrm{g}$ of sample were suspended in $5 \mathrm{ml}$ aqueous solution of 0.1 $\mathrm{M} \mathrm{Na} \mathrm{N}_{2}$ EDTA $(1 \mathrm{M} \mathrm{HCl})$ and stirred for 48 hours at room temperature. After washing and drying the samples were measured by EPR.

\section{Washing procedures for iron-zirconia reference samples} Bulk iron oxides treated in oxygen at high temperatures are in general only partially soluble in mineral acids. The ironpromoted samples, which potentially have iron present on the surface as $\mathrm{Fe}_{2} \mathrm{O}_{3}$ particles were thus also subjected to acidic digestion. The sample $(0.25 \mathrm{~g})$ was mixed with $\mathrm{KHSO}_{4}(1.5 \mathrm{~g})$ and heated first to $523 \mathrm{~K}$ for 30 min (clear melt) and then to $673 \mathrm{~K}$ for 15 to $45 \mathrm{~min}$. The resulting gray mass was dissolved in diluted sulfuric acid; the solid residue was washed by water, centrifuged, and dried at $373 \mathrm{~K}$.

\section{Washing procedures for iron-promoted catalyst}

About $100 \mathrm{mg}$ sample were suspended in $5 \mathrm{ml} 0.1 \mathrm{M}$ oxalic acid and stirred at room temperature. All samples were washed first for $2 \mathrm{~h}$. Three out of four samples underwent a second washing step in $5 \mathrm{ml}$ of fresh $0.1 \mathrm{M}$ oxalic acid after decanting of the initial washing liquid. The second washing step lasted 4 h $40 \mathrm{~min}, 20 \mathrm{~h} 40 \mathrm{~min}$, or 44 h $40 \mathrm{~min}$, respectively. The samples were washed twice with $5 \mathrm{ml} \mathrm{H}_{2} \mathrm{O}$ and were then separated from the liquid by centrifugation and decanting before they were dried at $383 \mathrm{~K}$. Washing liquids tested positively for sulfate ions (precipitate formation with $\left.\mathrm{Ba}^{2+}\right)$.

\section{Ion scattering spectroscopy}

The powders were pressed between two sheets of indium, which was freshly cut from a bar (Goodfellow, $99.999 \%$ ), yielding a homogeneous sample layer embedded in indium. Spectra were acquired on a Leybold LHS 12 MCD instrument with a hemispherical analyzer, using $2 \mathrm{keV} \mathrm{He}^{+}$ions and a flood gun.

\section{X-ray diffraction}

XRD measurements were taken in transmission geometry with a STOE STADI-P X-ray diffractometer using $\mathrm{Cu} \mathrm{K \alpha}$ radiation $(\lambda=1.542 \AA)$ with a focusing Ge primary monochromator. The diffracted radiation was measured using a position-sensitive detector. The samples were measured in part using $\alpha-\mathrm{Al}_{2} \mathrm{O}_{3}$ as an internal standard, mixed in a $1: 1$ weight ratio with the samples. The zirconia lattice constants were refined using the software PowderCell v2.4. ${ }^{55}$ For representation of the unit cell volume as a function of promoter content, wt $\% \mathrm{Fe}$ or $\mathrm{Mn}$ were converted into mol\% according to the following formula:

$$
m o l \% M=100 \times \frac{\frac{w t \% M}{M W(M)}}{\frac{w t \% M}{M W(M)}+\frac{100-w t \% M-\frac{w t \% M}{M W(M)} \times 1.5 \times M W(O)}{M W\left(\mathrm{ZrO}_{2}\right)}}
$$

M stands for metal ( $\mathrm{Fe}$ or $\mathrm{Mn}$ ), MW for molecular weight. This formula assumes an average promoter oxidation state of +3 and is valid for sulfate-free samples only. For sulfate containing samples, $4.5 \mathrm{wt} \% \mathrm{SO}_{3}$ were accounted for in the total weight balance.

\section{X-ray absorption spectroscopy}

Fe K edge spectra were measured at Hamburger Synchrotron Radiation Laboratory (HASYLAB) at beamline E4 in the fluorescence mode using a 5 element Ge detector at $90^{\circ}$ to the incident beam. The detector channels were adjusted to measure an approximately $600 \mathrm{eV}$ energy range including the $\mathrm{K} \alpha$ radiation at $6403 \mathrm{eV}$ and excluding scattered radiation with greater than $7000 \mathrm{eV}$ energy. The samples $(80 \mathrm{mg})$ were mixed with PE $(120 \mathrm{mg})$ and pressed into $13 \mathrm{~mm}$ pellets. The XAS data are presented as the averaged fluorescence signal divided by the incident beam signal. The spectra were energy calibrated to the first inflection of a simultaneously measured Fe foil $(7112 \mathrm{eV})$, and a linear background was subtracted from each file.

\section{Electron paramagnetic resonance}

Continuous-wave EPR spectra were recorded on a JEOL $J E S-R E 2 X$ system at $\mathrm{X}$-band frequency and temperatures from 293 to $130 \mathrm{~K}$. The spectra were measured at a microwave frequency of ca. $9.05 \mathrm{GHz}$ with a microwave power of $5 \mathrm{~mW}$, modulation amplitude of $0.4 \mathrm{mT}$, time constant $0.1 \mathrm{~s}$ and a modulation frequency of $100 \mathrm{kHz}$. The $\mathrm{g}$ and $\mathrm{A}$ values were calibrated using $\mathrm{Mn}^{2+}$ (nuclear spin $\mathrm{I}=5 / 2$ ) embedded in $\mathrm{MgO}$ as standard and $\mathrm{DPPH}$ (2,2-diphenyl-1-picryl-hydrazil; $\mathrm{g}=2.0036)$ as additional standard. Experimental errors are: $\Delta \mathrm{g}= \pm 0.002, \Delta \mathrm{A}= \pm$ $3 * 10^{-4} \mathrm{~cm}^{-1}$. The influence of the atmosphere (vacuum) on the EPR spectra of $\mathrm{Mn}^{2+}$ was studied as follows: The samples were heated in high vacuum $\left(10^{-4} \mathrm{hPa}\right)$ for $1 \mathrm{~h}$ at $423 \mathrm{~K}$ in the EPR tube and then measured. Subsequent measurement was performed after direct introduction of pure oxygen at room temperature.

\section{Catalytic tests}

The test reaction, the isomerization of $n$-butane, was run in a fixed bed tubular plug flow reactor, employing $500 \mathrm{mg}$ of catalyst. The effluent stream was analyzed by on-line gas chromatography with flame ionization detection (Varian 3800, $60 \mathrm{~m}$ Chrompack Silica PLOT capillary column). The samples were activated at $723 \mathrm{~K}$ and then cooled to the reaction temperature of $338 \mathrm{~K}$ (promoted sulfated zirconia) or $358 \mathrm{~K}$ (unpromoted sulfated zirconia), all in a $50 \mathrm{ml} \mathrm{min}^{-1}$

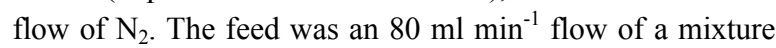
of 1 vol.\% $n$-butane in $\mathrm{N}_{2}$ at atmospheric pressure with about 20 ppm of isobutane as only detectable impurity; the 
value of $20 \mathrm{ppm}$ was subtracted from the isobutane concentration in the effluent stream.

\section{Results}

\section{Sample appearance}

All samples deepened in color with increasing promoter content. The uncalcined Mn-containing reference samples varied in color from pink via rosy brown $(1 \mathrm{wt} \%)$ to reddishbrown $(>3.5 \mathrm{wt} \%)$. After calcination, the samples were bluish-gray (up to $0.5 \mathrm{wt} \%$ ) to dark-brown (3.5 wt $\%$ ). The uncalcined Fe-containing samples displayed colors from offwhite (up to $0.5 \mathrm{wt} \%$ ) via yellow-beige (up to $2.5 \mathrm{wt} \%$ ) to ochre ( $>3 \mathrm{wt} \% \mathrm{Fe}$ ). The calcined reference Fe samples had more or less the same color as the uncalcined ones; some were a shade darker. At an equal Mn content of $2 \mathrm{wt} \%$, the freshly calcined co-precipitated reference sample was slightly more bluish than the sulfate-containing incipient wetness-prepared catalyst. In the case of promotion with $2 \%$ $\mathrm{Fe}$, the sulfate-containing incipient wetness-prepared catalyst was more orange-red than the corresponding reference sample.

\section{X-ray diffraction}

Diffractograms were recorded only of calcined samples. Figure 1 shows examples of diffractograms taken from MnZc (coprecipitated) and MnSZi (impregnated) samples, specifically an MnZc sample with $1.36 \mathrm{wt} \% \mathrm{Mn}$ and an

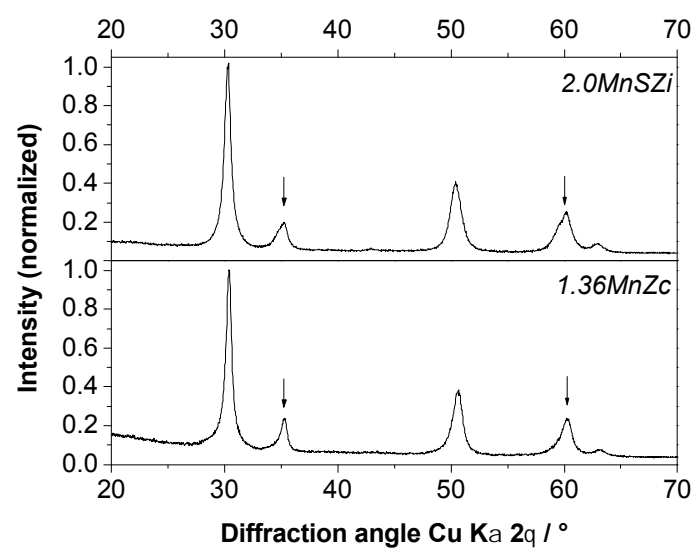

Figure 1: Diffractograms of a co-precipitated Mn-doped sample 1.36MnZ (top) and of an impregnated Mn-doped sample 2.0MnSZi (bottom). Normalized to maximum intensity.

MnSZi sample with $2 \mathrm{wt} \% \mathrm{Mn}$. For all Mn-containing reference samples, with between 0.27 and 3.53 wt $\% \mathrm{Mn}$, the diffractograms were devoid of contributions from the monoclinic phase. Incipient-wetness prepared samples sometimes showed traces of monoclinic $\mathrm{ZrO}_{2}$ at low Mn contents $(0.5$ $w t \%)$ but not for the higher contents. No reflections indicative of any manganese oxides were observed (maximum $\mathrm{Mn}$ content $5 \mathrm{wt} \%)$. A difference between the coprecipitated, sulfate-free reference material and the promoted catalyst material becomes evident from the reflections at around 35 and $60^{\circ}$. The separation into two reflections, which is indicative of the tetragonal phase, is clearly recognizable for the catalyst while for the reference material there seems to be only a single reflection as would be the case for the cubic phase. It is reported in the literature, that for highly disordered or very small crystallites the tetragonal and the cubic phase are difficult to distinguish by $\mathrm{X}$-ray diffraction and that the cubic fraction may be underestimated. ${ }^{56,57}$ Because the peaks are still asymmetric, the diffractograms were fit with the pattern of the tetragonal phase. However a mixture of tetragonal and cubic phase can not be excluded. The size of the crystalline domains (tetragonal phase) in all Mndoped samples was within 100-120 $\AA$ without any trend with the Mn content.

In Figure 2, diffractograms of sulfated zirconia and 2\% Fepromoted sulfated zirconia (FeSZi) are presented; the narrow reflections in these patterns originate from an internal

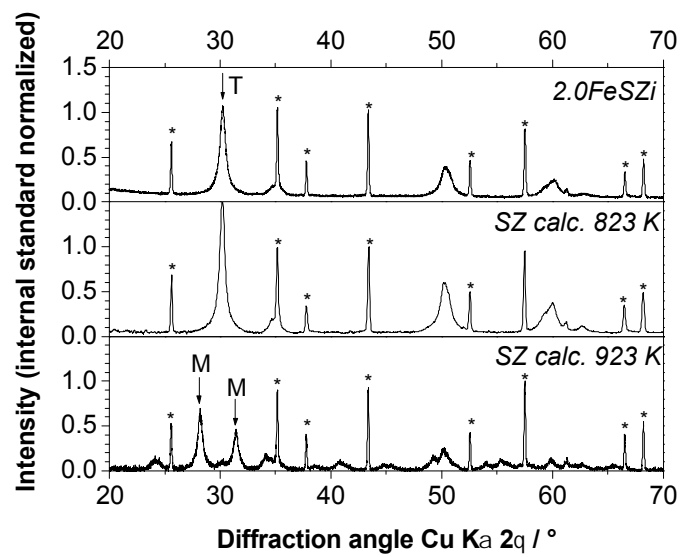

Figure 2: Diffractograms of an impregnated Fe-doped sample 2.0FeSZi (top) and of sulfated zirconia calcined at $823 \mathrm{~K}$ (middle) and at $923 \mathrm{~K}$ (bottom). Asterisks indicate peaks from internal standard $\alpha-\mathrm{Al}_{2} \mathrm{O}_{3}$. Normalized to reflection at $43.4^{\circ}$.

standard $\alpha-\mathrm{Al}_{2} \mathrm{O}_{3}$. None of the diffractograms of the Fedoped samples, which ranged from 0.26 to $5 \mathrm{wt} \%$ in Fe content, exhibited reflections of the monoclinic phase. At an Fe content of $5 \mathrm{wt} \%$ in the impregnated promoted sulfated zirconia, $\alpha-\mathrm{Fe}_{2} \mathrm{O}_{3}$ was detected. Similar differences between co-precipitated and impregnated samples were observed as for the $\mathrm{Mn}$ doped samples, i.e. the reflections at 35 and $60^{\circ}$ were not clearly separated for the co-precipitated materials. The diffractograms were also fit with the tetragonal pattern. The size of the crystalline domains in the Fe-doped samples varied between 100-160 $\AA$ without correlation to the $\mathrm{Fe}$ content.

SZ calcined at $823 \mathrm{~K}$ contained no or only a small amount of monoclinic phase, while calcination at $923 \mathrm{~K}$ produces a predominantly monoclinic zirconia sample as shown in Figure 2. Typically, the monoclinic fraction increases with in- 
creasing treatment temperature ${ }^{58-62}$ when initially amorphous material is calcined, and this is reproduced in our results. In comparison of unpromoted and promoted SZ, the presence of Fe or Mn clearly reduces the amount of monoclinic phase that is formed during calcination at $923 \mathrm{~K}$.

Figure 3 shows the results of refinement of the lattice constants of tetragonal zirconia $\left(\mathrm{P} 4_{2} / \mathrm{nmc}\right)$ to the XRD data; specifically the unit cell volume of the tetragonal phase is

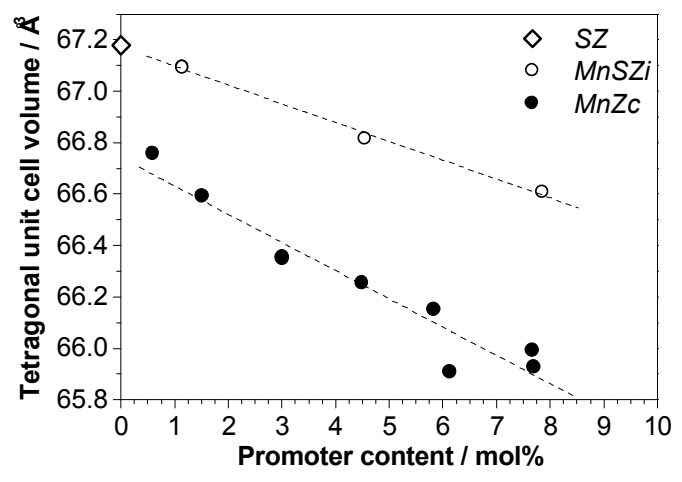

Figure 3: Tetragonal unit cell volume vs. promoter content in $\mathrm{mol} \%$ for sulfated zirconia (diamond), co-precipitated Mn-doped series MnZc (full circles), and impregnated Mndoped series MnSZi (open circles).

plotted vs. the promoter content. The largest unit cell volume was observed for a promoter content of zero, i.e. for sulfated zirconia. Both the coprecipitated samples and the sulfate-containing incipient wetness samples show a more or less linear decrease of the unit cell volume with increasing Mn content. The coprecipitated samples have a unit cell volume that is about $0.5 \%$ smaller and decreases more rapidly with increasing promoter content than that of the impregnated samples. The data points of the impregnated samples are in line with that of sulfated zirconia. Shrinkage of the unit cell volume is predominantly caused by a shortening along the $\mathrm{c}$ axis. In principle similar observations were made for the Fe containing co-precipitated reference compounds, see Figure 4, which also showed shrinkage of the unit cell with increasing Fe content. For the Fe-doped sulfated zirconia prepared by the incipient wetness method there was seemingly a slight shrinkage of the unit cell volume with the promoter content; however, the change is smaller than the uncertainty. The data points were again in line with that of sulfated zirconia.

\section{Electron paramagnetic resonance}

Although a $\mathrm{Mn}^{2+}$ precursor was used, no signals were detected in the spectra of the uncalcined coprecipitated Mndoped samples. It is not likely that $\mathrm{Mn}$ has changed to an EPR silent oxidation state, but rather that an undefined environment of the $\mathrm{Mn}^{2+}$ ions leads to a broad distribution of crystal fields and thus fine structure parameters, ultimately yielding lines too broad to be observed.

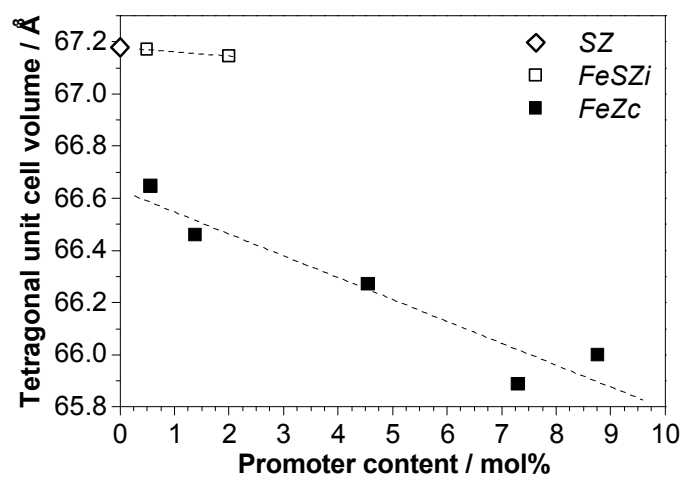

Figure 4: Tetragonal unit cell volume vs. promoter content in $\mathrm{mol} \%$ for sulfated zirconia (diamond), co-precipitated $\mathrm{Fe}$ doped series FeZc (full squares), and impregnated Fe-doped series FeSZi (open squares).

The EPR spectra of all calcined MnZc samples indicate the presence of $\mathrm{Mn}^{2+}(\mathrm{S}=5 / 2)$ in a distorted octahedral environment (Figures 5 and 6). Depending on the $\mathrm{Mn}^{2+}$ concentration the line widths of the signal at $\mathrm{g}=2.007$ and the resolution of the manganese hyperfine structure vary. For Mn contents $\leq 0.5 \mathrm{wt} \%$, the hyperfine structure $\left(\mathrm{I}\left({ }^{55} \mathrm{Mn}\right)=\right.$ $5 / 2)$ is well resolved $\left(\mathrm{A}\left({ }^{55} \mathrm{Mn}\right)=82 \cdot 10^{-4} \mathrm{~cm}^{-1}\right.$, assuming isotropic contributions only, line width $\Delta \mathrm{B}_{\mathrm{pp}}=2 \mathrm{mT}$, i.e. the $\mathrm{Mn}^{2+}$ centers do not show any mutual magnetic interactions. As an example, spectra of $0.27 \mathrm{MnZc}$ are presented in Figure 5 . The resolution of the spectra does not allow for identification of forbidden EPR transitions $\left(\Delta \mathrm{m}_{\mathrm{I}}= \pm 1\right)$ between the

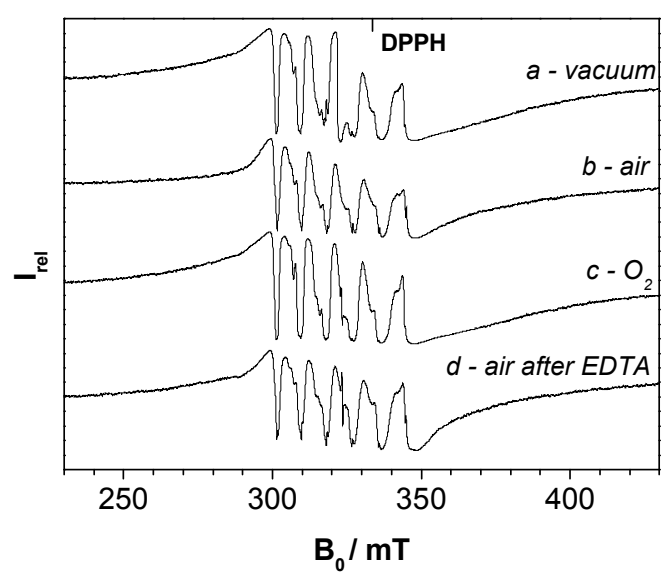

Figure 5: X-band EPR spectra of MnZc samples (0.27 wt\%) at $\mathrm{T}_{\mathrm{rec}}=150 \mathrm{~K}$ in different atmospheres: a - after evacuation at $\mathrm{T}=423 \mathrm{~K}$ for $1 \mathrm{~h}\left(10^{-4} \mathrm{mbar}\right), \mathrm{b}-$ after exposure to air, $\mathrm{c}$ - after exposure to pure oxygen at room temperature and $\mathrm{d}$ after treatment with EDTA solution for 48 hours. The spectra are superimposed by the $\mathrm{Mn}^{2+} / \mathrm{MgO}$ sextet of the standard, small sharp lines.

sextet lines; however, they cannot be excluded. The EPR parameters are very similar to those for $\mathrm{Mn}^{2+}$ in an octahe- 
dral environment in the lattice of $\mathrm{MgO}$. For Mn contents > $0.5 \mathrm{wt} \%$, the signal at $\mathrm{g}=2.007$ is superimposed by a broad symmetric line of $\mathrm{Mn}^{2+}$ species dominated by dipol-dipol broadening due to $\mathrm{Mn}^{2+}$ species in close proximity. The spectra of the $1.36 \mathrm{MnZc}$ sample, which demonstrate such behavior, are shown in Figure 6.

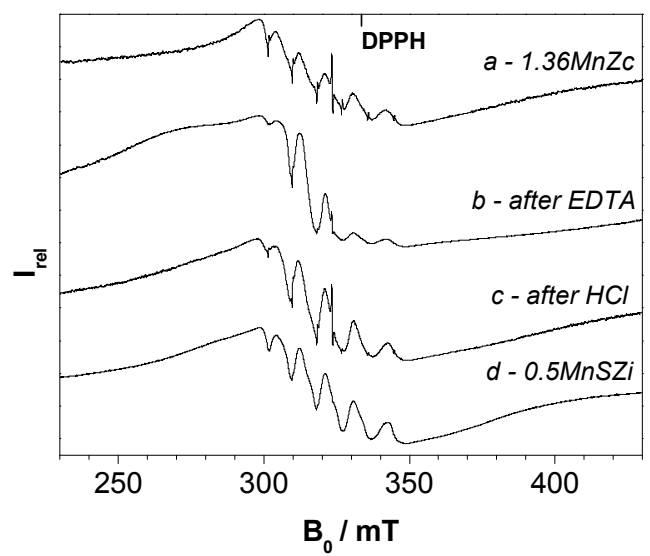

Figure 6: X-band EPR spectra of Mn-doped samples recorded at $\mathrm{T}_{\text {rec }}=150 \mathrm{~K}$. Co-precipitated reference sample after different treatments: $1.36 \mathrm{MnZc}$ a - before , $\mathrm{b}-$ after $48 \mathrm{~h}$ treatment with $0.1 \mathrm{M}$ EDTA, $\mathrm{c}-$ after $48 \mathrm{~h}$ treatment with $0.1 \mathrm{M} \mathrm{HCl}$. Impregnated Mn-doped catalyst $\mathrm{d}-0.5 \mathrm{MnSZi}$. The spectra are superimposed by the $\mathrm{Mn}^{2+} / \mathrm{MgO}$ sextet of the standard, small sharp lines.

In order to distinguish surface from bulk species, two types of experiments were conducted. The first series of measurements is given by the spectra in Figure 5, which were obtained of the $0.27 \mathrm{MnZc}$ sample in different environments, i.e. vacuum (5a), air (5b), and oxygen (5c). If the $\mathrm{Mn}^{2+}$ ions were accessible to the gaseous paramagnetic oxygen, the line widths should be broadened. This effect is expected to be pronounced for isolated species showing well resolved hyperfine structure and narrow lines as the MnZc samples with lower manganese content do. The line widths did not change significantly in the spectra recorded of $0.27 \mathrm{MnZ}$ in different atmospheres and vacuum, indicating that these $\mathrm{Mn}^{2+}$ species do not represent surface species. In the second series of experiments, documented by Figures $5 \mathrm{~d}$ and $6 \mathrm{a}-6 \mathrm{c}$, it was attempted to remove surface Mn species by suspending the samples for $48 \mathrm{~h}$ in $0.1 \mathrm{M}$ EDTA (or $1 \mathrm{M} \mathrm{HCl}$ ). The spectra of $0.27 \mathrm{MnZc}$ before (Figures $5 \mathrm{a}-5 \mathrm{c}$ ) and after washing (Figure 5d) are very similar, as are the spectra of $1.36 \mathrm{MnZc}$ before (Figure 6a) and after the washing procedures (Figures $6 \mathrm{~b}, 6 \mathrm{c}$ ), indicating that the majority of $\mathrm{Mn}$ species was unaffected. The two samples $0.27 \mathrm{MnZc}$ and $1.36 \mathrm{MnZc}$ were also treated with $\mathrm{HCl}$, a procedure which is reported to dissolve $\mathrm{MnO}, \mathrm{Mn}_{2} \mathrm{O}_{3}, \mathrm{Mn}_{3} \mathrm{O}_{4}$, and $\mathrm{MnO}_{2}{ }^{44}$ The solubility of manganese oxide species will, however, strongly depend on the temperature and duration of previous treatments and on the crystallite size. For samples with low manganese content $(0.27 \mathrm{wt} \%)$ neither the signal intensity nor the spectral parameters changed. The resolved hyperfine structure (sextet) of $\mathrm{Mn}^{2+}$ did not change for the higher manganese content sample (1.36 wt\%). However, the broad line at $\mathrm{g} \approx 2$ superimposing the sextet changes its structure and g-value. This is due to restructuring of the coordination sphere around the $\mathrm{Mn}^{2+}$ species as a result of the treatment with $\mathrm{HCl}$ or EDTA solution, respectively. The previously octahedral symmetry around the manganese is increasingly disturbed as is evident from the shift of a shoulder toward lower field and lower g-values, indicating that these species are surface species.

EPR spectra of Mn-promoted sulfated zirconia with low Mn content $(0.5 \mathrm{wt} \%)$ showed the same features as the references samples, i.e. a well-resolved hyperfine splitting superimposed by a broader band (Figure 6d). At a Mn content of $2 \mathrm{wt} \%$, only a very broad signal was detectable.

Only an EPR signal at $\mathrm{g}=4.1$ was observed for the uncalcined Fe-doped reference samples. All spectra of the calcined Fe-containing reference samples are a superposition of several signals with varying relative intensities arising from $\mathrm{Fe}^{3+}$ ions in different coordination environments (Figure 7).

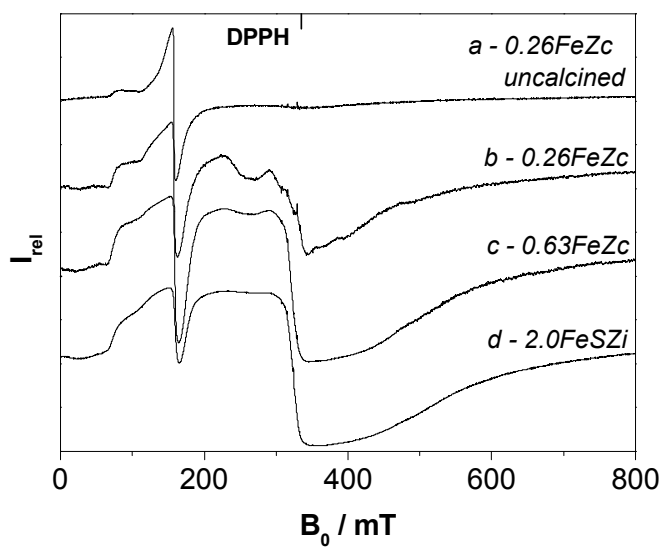

Figure 7: Typical X-band EPR spectra of Fe-doped samples recorded at $T_{\text {rec }}=150 \mathrm{~K}$ for different $\mathrm{Fe}$ concentrations. Coprecipitated reference samples: $\mathrm{a}-0.2 \mathrm{FeZc}$ before and $\mathrm{b}-$ after calcination, $\mathrm{c}-0.63 \mathrm{FeZc}$ after calcination. Impregnated Fe-promoted sulfated zirconia: $\mathrm{d}-2.0 \mathrm{FeSZi}$. The spectra are superimposed by the $\mathrm{Mn}^{2+} / \mathrm{MgO}$ sextet of the standard, small sharp lines.

The spectral patterns are dominated by the fine structure parameters D and E, which are strongly influenced by the symmetry of the paramagnetic centers. Accordingly, $\mathrm{Fe}^{3+}$ can give rise to a large variety of resonances over a wide range of effective g-values. ${ }^{63}$ The signal at $\mathrm{g}_{\text {eff }}=4.1$ is assigned to isolated $\mathrm{Fe}^{3+}$ in cubic symmetry with a strong rhombic distortion, with $\mathrm{E} / \mathrm{D} \approx 1 / 3$. The broad and intense signal at $\mathrm{g}=2.030$ arises from antiferromagnetically coupled $\left\{\mathrm{Fe}^{3+}-\mathrm{O}^{2-}\right\}$ clusters (small D) or $(\alpha-) \mathrm{Fe}_{2} \mathrm{O}_{3}$ particles; its intensity and line width varies expectedly with the iron content and particle size. However, this variation is not simple. Increasing cluster sizes can have different effects than the formation of crystalline antiferromagnetic $\alpha-\mathrm{Fe}_{2} \mathrm{O}_{3} .{ }^{64} \mathrm{Ac}$ - 
cordingly, a quantitative interpretation of these spectra will be difficult and can lead to misinterpretation.

For very low Fe concentrations $(\leq 0.5 \mathrm{wt} \%)$ the signal at $\mathrm{g}=$ 2.030 is structured, indicating different $\mathrm{Fe}^{3+}$ species in cubic symmetry (slightly distorted oxygen octahedron, smaller zero field splitting); signals at $\mathrm{g}_{\text {eff }} \approx 2.6$ (and 3.2) are also observed. In some cases a sharp signal at $\mathrm{g} \approx 2$ is present. To identify surface and bulk species, different experiments were performed to dissolve iron species. Neither stirring in solutions of oxalic acid for several days nor acidic digestion with $\mathrm{KHSO}_{4}$ removed all iron species completely from zirconia. Figure 8 shows spectra of $0.26 \mathrm{FeZc}$ before (Figure $8 \mathrm{a}$ ) and after digestion at different temperatures (Figure $8 \mathrm{~b}, 8 \mathrm{c}$ ).

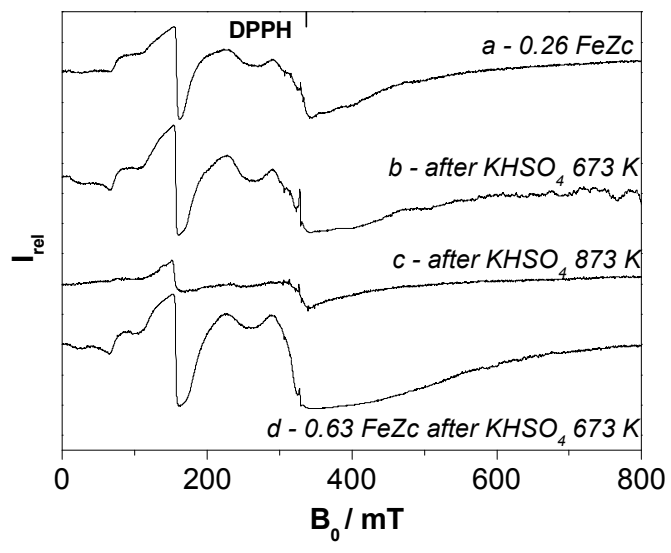

Figure 8: X-band EPR spectra of Fe-doped coprecipitated reference samples FeZc $(0.26$ and $0.63 \mathrm{wt} \%)$ at $\mathrm{T}_{\text {rec }}=150 \mathrm{~K}$ before and after acid digestion with $\mathrm{KHSO}_{4}$ (melt; see text): $\mathrm{a}-0.26 \mathrm{FeZc}$ before and $\mathrm{b}-$ after $45 \mathrm{~min}$ at $\mathrm{T}=673 \mathrm{~K}$ in the melt and $\mathrm{c}-0.26 \mathrm{FeZc}$ after $30 \mathrm{~min}$ at $\mathrm{T}=873 \mathrm{~K}$ in the melt, $\mathrm{d}-0.63 \mathrm{FeZc}$ after $45 \mathrm{~min}$ at $\mathrm{T}=673 \mathrm{~K}$ in the melt. The spectra are superimposed by the $\mathrm{Mn}^{2+} / \mathrm{MgO}$ sextet of the standard, small sharp lines.

Treatment at $673 \mathrm{~K}$ (Figure $8 \mathrm{~b}$ ) did not visibly change the spectrum, i.e. no Fe was removed, while digestion at $873 \mathrm{~K}$ (Figure 8c) led to a decrease in all Fe signals. This is due to the beginning of dissolution of the zirconia lattice, and the reduced signal intensity is due to the small amount of catalyst that remained after all treatments. Obviously, the selective dissolution of the supported iron oxides by acid digestion $\left(\mathrm{KHSO}_{4}\right.$ melt) did not succeed before the beginning of dissolution of the zirconia support, which can be brought into solution also by this procedure. Analogous effects were observed for samples with $0.63 \mathrm{wt} \%$ Fe (Fig. $8 \mathrm{~d})$. The signal at $\mathrm{g}=4.1$ was not reduced at all by the oxalic acid or $\mathrm{KHSO}_{4}$ treatment. For higher iron contents the signals at $\mathrm{g}=2.030$ and $\mathrm{g}_{\text {eff }}=2.6 / 3.2$ are partially reduced in intensity (EPR signal double integration) and their line widths were changed indicating that these species were located on the surface.

As already mentioned, for higher Fe contents ( $\geq 2 \mathrm{wt} \%)$ the quantitative interpretation of the EPR spectra of the strongly magnetically interacting iron (oxide) species (as in $\alpha-\mathrm{Fe}_{2} \mathrm{O}_{3}$ ) is very difficult. The removal of some smaller iron oxide clusters or crystallites may not show remarkable effects on the EPR line intensity because the highest contribution originates from larger $\mathrm{Fe}_{2} \mathrm{O}_{3}$ crystallites, which are expected to be much more difficult to dissolve.

The incipient wetness prepared Fe-doped samples showed essentially the same features as the references samples, as an example the spectrum of a $2.0 \mathrm{FeSzi}$ sample is presented in Figure $7 \mathrm{~d}$. Again, the signal at $\mathrm{g}=4.1$, indicative of isolated $\mathrm{Fe}^{3+}$ is present.

\section{Ion scattering spectroscopy}

Only the sulfate-containing incipient wetness prepared catalysts were analyzed with this method. All ISS spectra showed intense signals of oxygen (broad signal around 815 $\mathrm{eV}$ ) and zirconium (1675 eV). The signal of sulfur (ca. 1255 $\mathrm{eV}$ ) was very weak and disappeared after the first few scans because the sample was being sputtered while being analyzed. The signals of $\mathrm{Mn}$ and $\mathrm{Fe}$, if detected, were located in the range $1520-1525 \mathrm{eV}$. These positions are shifted by about $75 \mathrm{eV}$ with respect to the expected value as a result of charging. The top and the bottom spectrum in Figure 9 represent promoted sulfated zirconia samples containing $2 \mathrm{wt} \%$

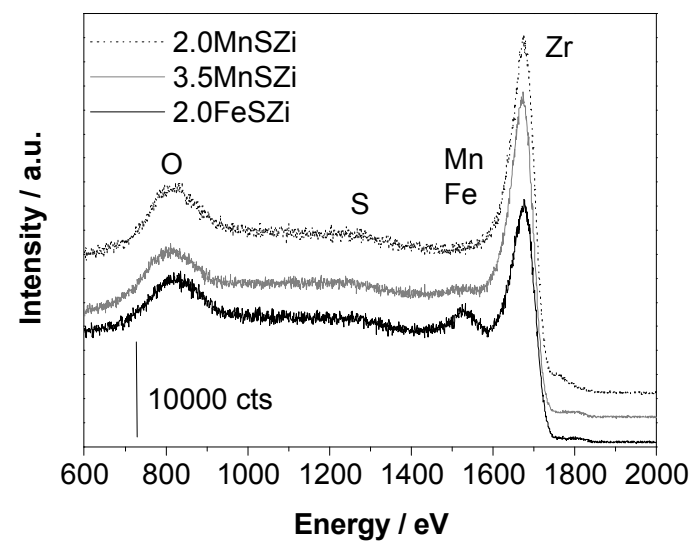

Figure 9: Ion scattering spectra $\left(2 \mathrm{keV} \mathrm{He}^{+}\right)$of promoted sulfated zirconia catalysts prepared via impregnation with different $\mathrm{Fe}(2.0 \mathrm{wt} \%$ ) and Mn content (2.0 and $3.5 \mathrm{wt} \%$ ) : a $-2.0 \mathrm{FeSZi}, \mathrm{b}-2.0 \mathrm{MnSZi}$, and $\mathrm{c}-3.5 \mathrm{MnSZi}$.

Mn or $2 \mathrm{wt} \% \mathrm{Fe}$, respectively. At this promoter content, $\mathrm{Fe}$ was detected on the surface while Mn was not. At a nominal Mn content of $3.5 \mathrm{wt} \%$, a weak Mn signal appeared in the spectrum (Figure 9 middle).

\section{X-ray absorption spectroscopy}

Figure 10a shows the near edge spectra of a calcined 2.0FeSZi sample, and the same sample after 1 to 4 washing cycles. After the first washing cycle the edge jump height is reduced by $23 \pm 3 \%$ indicating a corresponding loss of $\mathrm{Fe}$ from the sample, after the second washing cycle the edge jump height indicates that the sample has lost about $42 \pm 3 \%$ of the Fe present in the calcined sample. Further washing did not reduce the amount of $\mathrm{Fe}$ in the sample. The XANES 
spectra of the calcined sample and those of the washed samples do not match any reference $\mathrm{Fe}$ compound that we have measured, viz. $\mathrm{Fe}_{3} \mathrm{O}_{4}, \mathrm{Fe}_{2} \mathrm{O}_{3}, \mathrm{Fe}\left(\mathrm{NO}_{3}\right)_{3}, \mathrm{FeSO}_{4}, \mathrm{Fe}_{2}\left(\mathrm{SO}_{4}\right)_{3}$.

a)

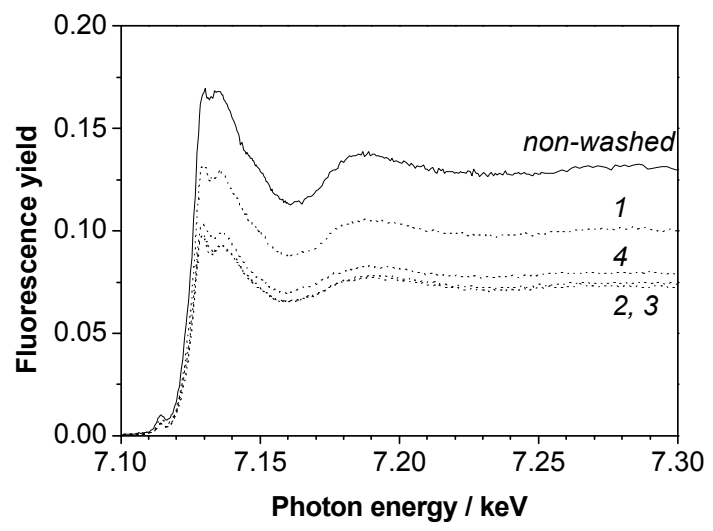

b)

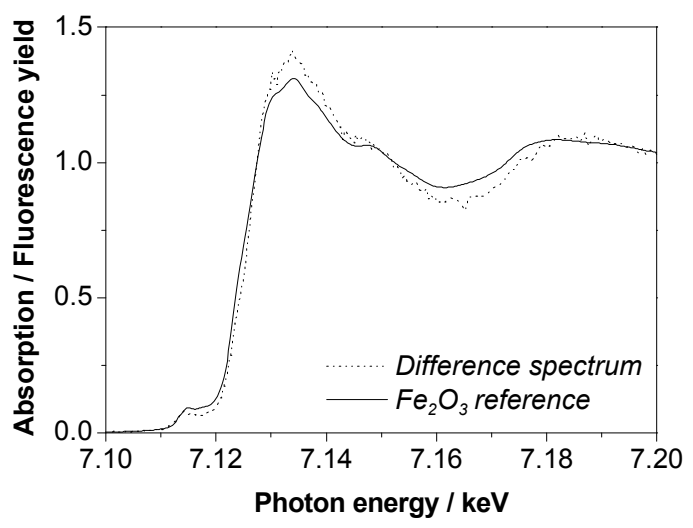

Figure 10: a) Fe K edge X-ray absorption spectra of impregnated sample $2.0 \mathrm{FeSZi}$ after a series of washing cycles in oxalic acid: before washing (solid line), 1-4: after $1^{\text {st }}$ through $4^{\text {th }}$ washing cycle (dotted lines); b) XANES difference spectrum of spectrum of unwashed samples and average of spectra 2-4 (dotted line) and $\mathrm{Fe}_{2} \mathrm{O}_{3}$ reference spectrum (solid line).

Figure $10 \mathrm{~b}$ shows the difference spectra of the calcined sample minus the average of the spectra taken after the $2^{\text {nd }}$, $3^{\text {rd }}$, and $4^{\text {th }}$ washing cycles. The shape of the difference spectra is similar to that of the XANES spectra of $\mathrm{Fe}_{2} \mathrm{O}_{3}$ also shown in Figure 10b, but not identical so that additional iron compounds, for instance sulfates, cannot be excluded.

Figure 11 shows the $n$-butane isomerization rate vs. time on stream profiles for sulfated zirconia and a number of incipient-wetness prepared catalysts. In order to obtain a measurable rate unpromoted sulfated zirconia was tested at $358 \mathrm{~K}$; the more active promoted materials were tested at $338 \mathrm{~K}$. The activities of Mn-promoted catalysts (11a) are within the same order of magnitude as those of Fe-promoted catalysts (11b); the promoting effect of $\mathrm{Mn}$ is thus verified. At equal promoter content, Mn actually produces a higher maximum activity, and at a promoter content of $0.5 \mathrm{wt} \%$ much better long-term activity than Fe. Typical is the slightly longer induction period of the $2 \mathrm{wt} \% \mathrm{Fe}$-promoted catalyst in comparison to the corresponding Mn-promoted catalyst. A pro-

a)

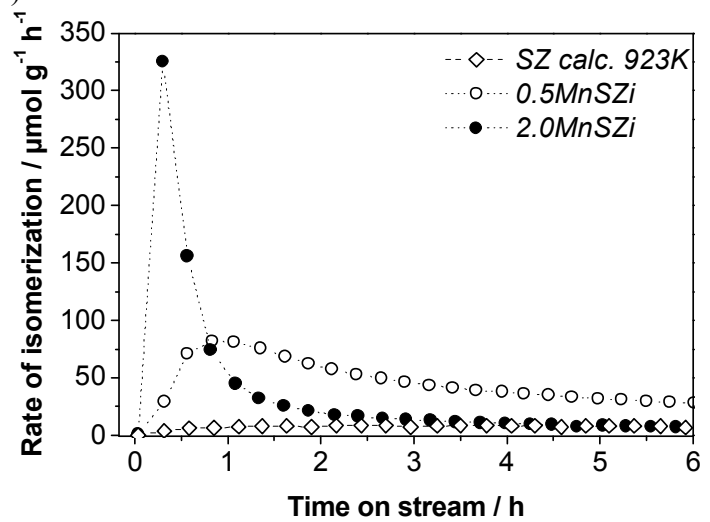

b)

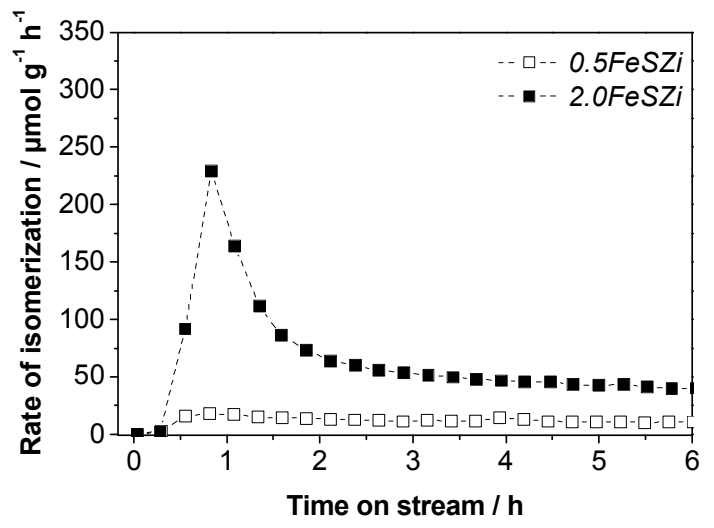

Figure 11: Rate of $n$-butane isomerization vs. time-onstream for a set of sulfated zirconia catalysts: a) sulfated zirconia calcined at $923 \mathrm{~K}$ (diamonds) and Mn-promoted sulfated zirconia (circles); b) Fe-promoted sulfated zirconia (squares). Open symbols: $0.5 \mathrm{wt} \%$, solid symbols: $2.0 \mathrm{wt} \%$. Conditions: $500 \mathrm{mg}$ catalyst, $n$-butane partial pressure $1 \mathrm{kPa}$ in nitrogen, total flow $80 \mathrm{ml} \mathrm{min}{ }^{-1}$ flow, reaction temperature $338 \mathrm{~K}$ for promoted sulfated zirconia, $358 \mathrm{~K}$ for unpromoted sulfated zirconia.

moter content of $2 \mathrm{wt} \%$ produces a higher maximum activity than a promoter content of $0.5 \mathrm{wt} \%$, but is associated with rapid deactivation.

\section{Discussion}

Reference samples: incorporation of $\mathrm{Fe}$ and $\mathrm{Mn}$ into the zirconia lattice

The reference samples were prepared following the procedures described by Stöcker, ${ }^{37,38}$ i.e. the base was added rapidly to ensure precipitation of $\mathrm{Fe}$ or $\mathrm{Mn}$ species and $\mathrm{Zr}$ species at the same time. In this way, a zirconium hydroxide raw material is obtained that is interspersed with Fe or $\mathrm{Mn}$ cations. Incorporation of these ions into the zirconia lattice 
as the sample crystallizes during calcination is then facilitated.

Stabilization of the tetragonal and the cubic phase of zirconia through solid solution formation has been investigated for a wide variety of foreign cations. Particularly yttriastabilized zirconia is technologically important. The general trend for such a stabilization is that at low (a few wt\%) dopant level the tetragonal phase is stabilized while at higher dopant level the cubic phase is stabilized. ${ }^{65}$ Our Mn- and Fedoped reference compounds parallel this phase behavior with increasing promoter content, which is an indication for incorporation.

Phase analysis by X-ray diffraction has been used to follow the incorporation of first row transition metal cations into zirconia; Stöcker, ${ }^{37,38}$ Valigi et al., ${ }^{44}$ and Keshavaraja and Ramasvamy investigated $\mathrm{Mn} ;{ }^{42}$ Stöcker, ${ }^{37,38}$ Navío et al. ${ }^{45}$, López et al., ${ }^{43}$ and Boot et al. ${ }^{47}$ investigated Fe. For Mn, all samples were prepared by a co-precipitation method, and stabilization of the tetragonal phase at low Mn content and of the cubic phase at high $\mathrm{Mn}$ content was reported. Valigi et al. ${ }^{44}$ found $100 \%$ cubic phase at $7.8 \mathrm{wt} \% \mathrm{Mn}$, Stöcker ${ }^{37}$ already at $3 \mathrm{~mol} \% \mathrm{MnO}(\approx 1.35 \mathrm{wt} \% \mathrm{Mn})$. López et al. ${ }^{43}$ detected only the tetragonal phase over a wide range of range of compositions ( $\mathrm{Mn}: \mathrm{Zr}$ from 1:9 to 9:1). For Fedoped samples prepared from mixed Fe, $\mathrm{Zr}$ - solutions by coprecipitation or gelation, stabilization of the cubic phase was reported by Stöcker, ${ }^{37,38}$ and of the tetragonal phase by Navío et al. ${ }^{45}$ (at 3-5 wt\% Fe). Boot et al. ${ }^{47}$ used a crystalline zirconia support and from their results excluded solid state reactions between support and Fe phase. Okamoto et al., ${ }^{49}$ using Mössbauer spectroscopy, found $\mathrm{Fe}$ incorporated into zirconia only when the sample was prepared by coprecipitation.

Zirconia lattice parameters have been analyzed more closely. Stöcker reported shrinkage of the parameter $a$ in cubic solid solutions of zirconia containing $\mathrm{Fe}$ and $\mathrm{Mn}^{38}$ Stöcker ${ }^{37}$ and also Valigi et al. ${ }^{44}$ reported a decrease of $c / a$ with increasing dopant level in tetragonal zirconia stabilized with $\mathrm{Mn}$. We find corresponding behavior for $\mathrm{Mn}$ and $\mathrm{Fe}$ doped reference compounds, and consistent with Valigi's results, mainly $c$ is decreasing and not so much $a$. Shrinkage of the zirconia unit cell volume with increasing dopant level is rather rare. Yashima et al., ${ }^{66}$ who investigated the validity of Vegard's law for solid solutions of cubic and tetragonal zirconia, compiled data on the unit cell volume and found an increasing volume with foreign cation content for calcium, yttrium, and a large number of rare earth elements, and a decreasing volume only for magnesium, germanium, and scandium. Decisive parameters for increasing or decreasing unit cell volume may be the size, the valence (lower valence may cause oxygen vacancies), and the location (substitutional or interstitial) of the incorporated ion. As an example, $\mathrm{Y}^{3+}$ is lower valent and larger than $\mathrm{Zr}^{4+}$; its local environment in the zirconia lattice ${ }^{67,68}$ has been debated, and its incorporation evokes an increase in the lattice parameter $c$ with increasing content. ${ }^{67}$ The $\mathrm{Mn}^{2+}$ ion with an effective ionic radius of $0.96 \AA$ (coordination number $\mathrm{CN}=8$ ) is lar- ger than the $\mathrm{Zr}^{4+}$ ion with $0.84 \AA$ (at $\mathrm{CN}=8$ ), while $\mathrm{Mn}^{3+}$ is smaller at $0.65 \AA(\mathrm{CN}=6)$, as is $\mathrm{Fe}^{3+}$ at $0.78 \AA(\mathrm{CN}=8) .{ }^{69}$

Stöcker and Valigi heated their samples initially in $\mathrm{H}_{2}$ and obtained thus almost exclusively $\mathrm{Mn}^{2+}$, and a treatment in oxygen at $753 \mathrm{~K}$ oxidized more than $70 \%$ of the manganese to $\mathrm{Mn}^{3+}$ and $\mathrm{Mn}^{4+} \cdot{ }^{44}$ As our reference samples were treated in an oxidizing atmosphere, it is likely that manganese is present not only as $\mathrm{Mn}^{2+}$ as detected by EPR but also in higher oxidation states, which are EPR silent. Preliminary results from optical spectroscopy indicate the presence of $\mathrm{Mn}^{3+}$ in the $\mathrm{Mn}$ reference samples. In Valigi's experiments, the slope for the shrinkage of the unit cell depended on the Mn oxidation state ${ }^{44}$ and was less steep for $\mathrm{Mn}^{2+}$ than for $\mathrm{Mn}^{3+} / \mathrm{Mn}^{4+}{ }^{44}$ Our slope (Figure 3) is steeper than those reported by Valigi and that reported by Keshavaraja for zirconia with incorporated $\mathrm{Mn}^{4+}$ but still only roughly $1 / 5$ of the slope created by incorporation of increasing amounts of scandium, another representative of the first row transition metals. ${ }^{66}$ Comparison of Valigi's and Kesharavaja's slopes gives no trend with the $\mathrm{Mn}$ oxidation state, suggesting that consistency may be obtained only within one set of samples but that other factors influence the unit cell volume.

At low Mn concentrations $(0.27 \mathrm{wt} \%)$, the EPR data indicate that $\mathrm{Mn}^{2+}$ ions are solely present as incorporated and isolated species (Figure 5). The EPR spectra are very similar to the spectra of $\mathrm{Mn}^{2+}$ incorporated in $\mathrm{Y}_{2} \mathrm{O}_{3}$-stabilized $\mathrm{ZrO}_{2}$ crystals as presented by Sasaki and Maier. ${ }^{70}$ The contribution of manganese surface species to the EPR spectra can be neglected in their work due to the macro-crystalline (singlecrystalline) character of the $\mathrm{ZrO}_{2}$. Sazaki and Maier also stated that the EPR results do not depend on the morphology of $\mathrm{ZrO}_{2}$, as evidenced by identical results obtained for single crystals, polycrystals, and powder samples. Nishizawa et al. ${ }^{71}$ who investigated $\mathrm{Mn}$ in calcia-stabilized zirconia even concluded from the sharpness of the lines that $\mathrm{Mn}^{2+}$ should not be in interstitial sites because then a broad range of local environments, equivalent to broadened EPR lines, would be expected. At a Mn content of $1.36 \mathrm{wt} \%$, the well-resolved hyperfine structure of the isolated $\mathrm{Mn}$ ions is superimposed by a broader signal (Figure 6). Nishizawa et al. ${ }^{71}$ inferred that such a superimposed single broad line, which increased with increasing calcium content in their samples, is characteristic of $\mathrm{Mn}^{2+}$ in a cubic zirconia crystal. Alternatively, dipole-dipole interaction of $\mathrm{Mn}$ ions in proximity inside the lattice could be responsible for such a broad line. The fact that washing has little effect on the EPR spectrum of $1.36 \mathrm{MnZc}$ indicates a high degree of incorporation at this Mn concentration.

For all calcined Fe-doped reference samples signals indicating several different species are observed in the EPR spectra, even at the lowest concentration of $0.26 \mathrm{wt} \% \mathrm{Fe}$ (Figure 7). The acid digestion attempts conducted with little effect on $0.26 \mathrm{FeZc}$ and $0.63 \mathrm{FeZc}$ are somewhat inconclusive as it is not clear if incorporated or resilient surface species did not dissolve (Figure 8). Taking into account all experimental (preparation, digestion), spectroscopic (EPR parameter and parameter variation, line widths and line widths variation) and literature arguments one can conclude that only the iron 
signal at $\mathrm{g}_{\text {eff }}=4.1$ corresponds to $\mathrm{Fe}^{3+}$ incorporated into the zirconia lattice. This $\mathrm{Fe}^{3+}$ species is also the only one found by Sasaki et al. ${ }^{70}$ for $\mathrm{Fe}^{3+}$ incorporated in $\mathrm{Y}_{2} \mathrm{O}_{3}$-stabilized $\mathrm{ZrO}_{2}$ single crystals, polycrystals, and powder samples.

With respect to the position and local environment of $\mathrm{Fe}$ and $\mathrm{Mn}$ in the zirconia lattice, it should be mentioned that not even for the well-investigated incorporation of yttrium are all details known. The yttria-zirconia system is considered a substitutional solution; clustering of oxygen vacancies and yttrium ions with the formation of $\mathrm{YO}_{6}$ units that can have near-octahedral coordination has been proposed, ${ }^{68}$ but other authors report an eight-fold coordination around yttrium inside tetragonal as well as cubic zirconia. ${ }^{67}$ Our EPR data are consistent with a highly symmetric environment for $\mathrm{Mn}^{2+}$ and $\mathrm{Fe}^{3+}$; we are currently investigating the exact nature of the surrounding by quantum-chemistry supported analysis of EPR spectra and fitting of EXAFS data.

For Mn, XRD and EPR data consistently point towards a high degree of incorporation: steady shrinkage of the unit cell with increasing Mn content (Figure 3), no success of washing experiments. Further support for incorporation of considerable amounts comes from Valigi et al. who did not observe (XRD) any manganese oxide at a content of 7.79 wt $\% \mathrm{Mn}$, but only at $11.5 \mathrm{wt} \%$. For Fe, the XRD data also reveal a steady shrinkage of the unit cell (Figure 4), but the EPR spectra indicate extra-lattice Fe species.

It would be intriguing to use the correlation between unit cell volume and promoter content as a calibration line to determine the incorporated fraction of promoter in any catalyst sample. However, for Mn the high likelihood for the simultaneous presence of several oxidation states renders this nearly impossible. Additionally, a decrease in $c / a$ was found at constant yttrium content with decreasing particle size (tuned by treatment temperature). ${ }^{72}$ The unit cell volume thus depends on several factors and is no simple measure of the promoter content. As the size of the crystalline domains in our reference samples did not have any particular trend with the promoter content, the particle size effect can be excluded.

\section{Evidence of incorporation of $\mathrm{Fe}$ or $\mathrm{Mn}$ in promoted sul- fated zirconia catalysts}

For the Mn-promoted sulfated zirconia samples that were prepared by the incipient wetness method, all data consistently point towards incorporation of the promoters into the zirconia lattice. XRD analysis reveals the stabilization of the tetragonal phase in comparison to Mn-free sulfated zirconia that was calcined under the same conditions (Figures 1 and 2). A shrinking unit cell volume with increasing Mn content is also observed (Figure 3), although the slope is not as steep as for the Mn reference materials. This does not automatically mean that incorporation into the bulk is incomplete as many parameters influence the unit cell volume and the presence of sulfate obscures the results. The intercept with the y-axis, i.e. the (projected) unit cell volume in absence of $\mathrm{Mn}$, is different for sulfated and non-sulfated samples (Figure 3). A strong argument for rather complete incorporation is given by the ISS data; no Mn is detected by this highly surface-sensitive method for lower Mn contents ( $2 \mathrm{wt} \%$ and less, Figure 9). Further evidence arises from $\mathrm{Mn} \mathrm{K}$ edge XANES spectra, ${ }^{18}$ which did not match the spectra of any of the references, i.e. $\mathrm{MnSO}_{4}, \mathrm{MnS}, \mathrm{MnO}, \mathrm{Mn}\left(\mathrm{NO}_{3}\right)_{2}, \mathrm{MnCO}_{3}$, $\mathrm{Mn}_{3} \mathrm{O}_{4}, \mathrm{MnOOH}, \mathrm{Mn}_{2} \mathrm{O}_{3}$, or $\mathrm{MnO}_{2}$, as would be expected for a $\mathrm{Mn}$ species in the zirconia lattice. The average $\mathrm{Mn}$ valence can be determined from the edge position, ${ }^{73}$ and for $2.0 \mathrm{MnSZi}$, a value of 2.7 was obtained. It is thus obvious that the $\mathrm{Mn}^{2+}$ species in a well-defined environment, which are detected by EPR and correspond to those detected in the reference samples, represent only a fraction of the Mn. Higher valent species are present but can not be identified using XAS, which only delivers an average valence. $\mathrm{Mn}^{3+}$ and $\mathrm{Mn}^{4+}$ are likely candidates, and it was shown by Valigi et al. ${ }^{44}$ that after treatment of $\mathrm{Mn} / \mathrm{ZrO}_{2}$ samples in oxidative atmosphere, $\mathrm{Mn}^{2+}, \mathrm{Mn}^{3+}$, and $\mathrm{Mn}^{4+}$ can coexist inside the zirconia lattice. In our incipient wetness prepared catalysts, $\mathrm{Mn}$ in different oxidation states seems to be largely incorporated into the zirconia bulk.

Little information is available in the literature on the state of $\mathrm{Mn}$ in sulfated zirconia promoted with $\mathrm{Mn}$ alone. ${ }^{2,5,17,18,19,23,31}$ Miao et al. ${ }^{19}$ suspected oxide solid solutions or highly dispersed surface species on the basis of diffractograms that did not show a Mn phase. The Mn content in the samples was only $1.5 \%$ metal, an amount most likely insufficient for detection by XRD, and no further evidence was delivered for solid solution formation. Srinivasan ${ }^{17}$ proposed "manganese oxide" on the surface of zirconia from TG-DTA-MS results of the thermal decomposition of precursors, and Yamamoto et al. ${ }^{5}$ suggested surface- $\mathrm{MnSO}_{4}$, referring to Mn K edge XAS spectra, which changed upon exposure of the sample to $n$-butane, as evidence $(0.27 \mathrm{wt} \%$ $\mathrm{Mn})$. Scheithauer et al. ${ }^{23}$ assigned a weak peak at $641 \mathrm{eV}$ in the XP spectrum to $\mathrm{Mn}^{2+}(1.8 \mathrm{wt} \% \mathrm{Mn})$. In mixed Fe, Mnpromoted sulfated zirconia, the Mn concentration is usually chosen so low that only limited statements on the nature of Mn can be made. ${ }^{3}$ Scheithauer et al. ${ }^{23}$ did not detect Mn by XPS and presented EPR spectra indicative of isolated $\mathrm{Mn}^{2+}$ (hyperfine splitting) in "unknown locations". Benaissa et al. ${ }^{27}$ could not find any Mn oxide particles with HRTEM. Miao's ${ }^{19}$ samples were made by co-precipitation of mixed $\mathrm{Zr}$, Mn solutions with a calcination temperature of $923 \mathrm{~K}$, Scheithauer ${ }^{23}$ used the incipient-wetness method to introduce the promoters and calcined at $923 \mathrm{~K}$, Benaissa et al. ${ }^{27}$ impregnated followed by calcination at $998 \mathrm{~K}$, and Yamamoto applied the equilibrium adsorption technique followed by calcination at $873 \mathrm{~K}$. Variations in the preparation conditions may favor formation of surface or bulk manganese species and mixtures of both may be obtained. A single technique such as XANES or EPR may not deliver sufficient information on all $\mathrm{Mn}$ species. Our results are consistent with the EPR data in Scheithauer's work and the suppositions by Miao; the formation of $\mathrm{MnSO}_{4}$ cannot be confirmed and may have been the result of the different preparation conditions applied by Yamamoto.

For incipient-wetness-prepared Fe-promoted sulfated zirconia, again the tetragonal phase is stabilized in comparison with unpromoted sulfated zirconia (Figure 2), suggesting 
incorporation of $\mathrm{Fe}$ into the zirconia lattice. The unit cell data (Figure 4) are, however, inconclusive in that there is no contraction of the lattice with increasing promoter content. Most literature and all of our data point towards Fe(III) as the single oxidation state and accordingly, other than for $\mathrm{Mn}$, the unit cell volume should be free of an influence of different oxidation states. Evidence for incorporation arises from EPR spectra (Figure 7d), which show the presence of isolated $\mathrm{Fe}^{3+}$ species in highly symmetric environment $(\mathrm{g}=$ 4.1). The EPR spectra also indicate oxidic Fe surface species, and the ISS data (Figure 9) confirm a considerable $\mathrm{Fe}$ surface concentration. Incorporation is thus by no means complete. Consistent with partial incorporation, and at variance with the results obtained for the reference compounds, the washing experiments succeeded in removing Fe (Figure 10). About $42 \%$ of the Fe could be removed by successive treatments; again, it is not guaranteed that all surface species dissolve in oxalic acid, i.e. the $42 \%$ represent a minimum amount for the surface species. In agreement with EPR data, the difference spectrum representing the washed-off component resembles that of $\mathrm{Fe}_{2} \mathrm{O}_{3}$; this interpretation is also consistent with the reddish color of the samples. In comparison to $\mathrm{Mn}, \mathrm{Fe}$ incorporation into the zirconia lattice is less complete when the materials are prepared by the incipient wetness method.

$\mathrm{Fe}$ as a single promoter has drawn more attention in the literature than Mn because there is agreement on its promoting effect and because it is the major component in the wellinvestigated mixed promoted $\mathrm{Fe}, \mathrm{Mn}$ sulfated zirconia (typically $1.5 \mathrm{wt} \% \mathrm{Fe}, 0.5 \% \mathrm{Mn}$ ). ${ }^{2,5,17,18,19,30,31,32,33,34,35}$ Hino and Arata $^{34}$ found an XPS signal of Fe-promoted sulfated zirconia $(2 \mathrm{wt} \% \mathrm{Fe})$ at $711.4 \mathrm{eV}$, which they rated as close to that of $\mathrm{Fe}_{2} \mathrm{O}_{3}$; Ardizzone and Bianchi ${ }^{33}$ assigned a peak at 710.9 $\mathrm{eV}$ to $\mathrm{Fe}_{2} \mathrm{O}_{3}$. Srinivasan et al. ${ }^{17}$ detected $\mathrm{Fe}_{2} \mathrm{O}_{3}$ in the diffractogram at $3 \mathrm{wt} \% \mathrm{Fe}$ content. Morterra et al. ${ }^{2}$ identified sulfate- and $\mathrm{OH}$-free, oxidized $\mathrm{Fe}$ species $\left(\mathrm{Fe}^{3+}\right)$ as centers of activity. Miao et al. ${ }^{19}$ argued in an analogous way for $\mathrm{Fe}$ as for $\mathrm{Mn}$, i.e. the absence of peaks in the diffractogram (at 1.5 $\mathrm{wt} \% \mathrm{Fe}$ ) was ascribed to formation of a solid solution or highly dispersed species; similarly Benaissa et al. ${ }^{27}$ could not find any $\mathrm{Fe}$ oxide species with HRTEM (at $1.5 \mathrm{wt} \% \mathrm{Fe}$ ). Yamamoto et al. ${ }^{5}$ favored the idea of an interstitial-type solid solution of $\mathrm{Fe}^{3+}$ in zirconia on the basis of XANES and EXAFS results, showing that Fe $\mathrm{K}$ edge spectra were unchanged upon admission of $n$-butane to the reactor. The authors also pointed out that the formation of a solid solution requires that zirconium hydroxide and not oxide is reacted with the $\mathrm{Fe}$ compound and that according to the $\mathrm{Fe}-\mathrm{Zr}$ $\mathrm{O}$ phase diagram, $\mathrm{Fe}_{2} \mathrm{O}_{3}$ (hematite) will be formed at high $\mathrm{Fe}$ concentration. The referenced phase diagrams, ${ }^{74}$ however, cover temperatures of $1373 \mathrm{~K}$ and higher. Millet et al. ${ }^{35}$ combined Mössbauer and XP spectroscopy and identified two $\mathrm{Fe}$ species, an isolated $\mathrm{Fe}^{3+}$ "at the surface or in the bulk near the surface of $\mathrm{ZrO}_{2}$ " and $\mathrm{Fe}_{2} \mathrm{O}_{3}$. In mixed Fe, Mn promoted sulfated zirconia, Scheithauer et al. ${ }^{23}$ and Tábora and Davis $^{3}$ are in agreement on the presence of small rafts of $\mathrm{Fe}_{2} \mathrm{O}_{3}$ on the surface of zirconia, whereby Tábora and Davis explicitly excluded solid solution formation although they prepared their catalyst by co-precipitation. While all these studies agree on iron being trivalent, Wan et al. ${ }^{26}$ proposed an $\mathrm{Fe}(\mathrm{IV})$ species. In light of the cited and our data, it appears that incorporated $\mathrm{Fe}^{3+}$ species and an $\mathrm{Fe}_{2} \mathrm{O}_{3}$-like surface species coexist, and the amount of each depends on the preparation conditions.

The differences in incorporation behavior of $\mathrm{Mn}$ and $\mathrm{Fe}$ are interesting with respect to understanding mixed $\mathrm{Fe}, \mathrm{Mn}$ promoted sulfated zirconia. Resasco and coworkers ${ }^{24,75}$ and García et al. ${ }^{36}$ have claimed that the main function of Mn is to help disperse $\mathrm{Fe}$ in these mixed promoted catalysts. These suppositions were made on the basis of a higher Fe/Zr intensity $^{36,75}$ ratio in XP spectra in the presence of Mn. We believe that an alternative interpretation emerges from our findings: as $\mathrm{Mn}$ is more easily incorporated than Fe it may be preferably incorporated, preventing incorporation of $\mathrm{Fe}$ and thus leading to a higher surface Fe concentration. Incorporation of $\mathrm{Mn}$ into the zirconia lattice in mixed promoted sulfated zirconia is also supported by data presented by Scheithauer et al. ${ }^{23}$ who did not detect Mn with XPS, although $0.5 \mathrm{wt} \% \mathrm{Mn}$ should be within the detection limit. XPS can thus easily mislead: usually, low promoter to support signal intensity ratios are interpreted as poor dispersion of the promoter on the surface, but if the promoter is incorporated, XPS will also give a low promoter to support intensity ratio.

\section{Implications of the presence of bulk and surface pro- moter species for catalysis}

The paramount question arising from the characterization of the manganese or iron promoted sulfated zirconia is whether surface or bulk species are responsible for the promoting effect. Unfortunately, the washing procedures performed on the FeSZi did not only remove the Fe surface species but also sulfate, so that the catalytic activity of these materials would not reflect that of an Fe-promoted sulfated zirconia with only bulk iron species.

Our catalysis results show that at a content of $0.5 \mathrm{wt} \%, \mathrm{Mn}$ has a stronger promotional effect than Fe (Figure 11). At a promoter content of $2 \mathrm{wt} \%$, the Mn-promoted catalyst exhibits higher activity than the Fe-promoted catalyst within the first hour; but after $5 \mathrm{~h}$ on stream the situation is reversed. Differences in assessment of promoters in the literature, in part, result from this rapid change in performance. The higher maximum rate (conversion) that is achieved at high promoter content is of questionable benefit as long as it is accompanied by rapid deactivation. The decline in isomerization rate may be a result of coking ${ }^{76}$ and it has been shown that high activity of promoted catalysts can be conserved by addition of $\mathrm{Pt}$ to the catalyst and $\mathrm{H}_{2}$ to the feed. ${ }^{77}$

At a $\mathrm{Mn}$ content of $2 \mathrm{wt} \%$, no $\mathrm{Mn}$ is detected at the surface by ISS, yet we find a high maximum activity. Either very few Mn surface atoms are responsible for a high turnover or there is indeed some promoting effect through $\mathrm{Mn}$ that is incorporated into the zirconia lattice. The distribution of $\mathrm{Mn}$ and $\mathrm{Fe}$ to surface and bulk is definitely very different, i.e. $\mathrm{Mn}$ is predominantly incorporated while $\mathrm{Fe}$ is to a significant extent present as surface species. Without knowing the 
role of the chemistry of the two elements, identification of surface or bulk species as origin of the promoting effect is difficult; variation of the surface and bulk fraction of a single element would allow for more conclusive statements.

An argument for a role of surface species in the promoting effect comes from Miao's tests. ${ }^{19}$ He prepared catalysts by co-precipitation, which should thus resemble our reference materials with a high degree of incorporation, and he observed a weak promoting effect for iron and a negative effect for Mn. On the other hand, some transition metals $(\mathrm{Cr})$ developed a good promoting effect despite the preparation method. Another argument for the relevance of surface species arises from Arata's ${ }^{78}$ experiments, which showed that sulfated zirconia can be promoted for butane isomerization by physically mixing it with $\mathrm{Fe}_{2} \mathrm{O}_{3}$. These mixtures were calcined at $673 \mathrm{~K}$ and above.

A number of arguments speak for the promoting effect being caused by $\mathrm{Mn}$ or Fe species in the bulk. First of all, the stabilization of the tetragonal phase should have a positive effect on the catalytic activity; the monoclinic phase has also been reported as active, but less so. ${ }^{79}$ It has been suspected that the promoters act by generating alkenes through oxidative dehydrogenation. ${ }^{25,35}$ If this was indeed the function of the promoters, then it would be remarkable that $\mathrm{Mn} / \mathrm{ZrO}_{2}$ is used as $n$-butane oxidation catalyst and works best if a solid solution is formed. ${ }^{41}$ Many first row transition metal cations $-\mathrm{Mn}, \mathrm{Fe}, \mathrm{Co}, \mathrm{Ni}-$ are promoters for sulfated zirconia and while their redox potentials are different they may all have a common function via incorporation. All these promoters feature stable oxidation states that are lower valent than zirconium in zirconia, meaning that their incorporation must lead to oxygen vacancies for charge compensation. Accordingly, the promoters change the structural and electronic properties of the catalysts' bulk. Near the surface such oxygen vacancies could create sites with a high degree of unsaturation, i.e. strongly acidic Lewis sites. However, sites of extraordinary acidity have not yet been found.

If the solid solution formation was crucial, one would hope for a correlation between catalytic performance and bulk structural data. For the Mn-doped samples, the catalytic activity seemingly improves with increasing contraction of the lattice. With further increasing promoter content, this positive effect is eventually diminished as bulk promoter oxides cover active surface sites. However, the data points are few, and no such correlation is seen for Fe-doped samples. Furthermore, catalysts that were made from the same raw material (same promoter content) by calcination in differently sized batches exhibit very similar unit cell parameters yet perform very differently in $n$-butane isomerization. ${ }^{54,80}$ It appears that there is no simple correlation of catalytic activity and unit cell parameters. However, as stated above, the unit cell volume is a function of several parameters and effects may cancel each other out, yielding coinciding unit cell data.

Experiments on the state of the promoters during or after reaction may deliver information on whether the promoters are directly involved into the isomerization reaction or not. Iron was found reduced to $\mathrm{Fe}^{2+}$ after $n$-butane isomerization, and oxidative dehydrogenation to give alkenes was suggested as the promoting effect. ${ }^{35}$ We have investigated the Mn valence by in situ XAS during $n$-butane isomerization and could not detect a change of oxidation state throughout the entire reaction profile. ${ }^{81,82}$ Yamamoto et al. observed a change in the Mn K edge data upon exposure to $n$-butane while the Fe K edge remained unaffected. ${ }^{5}$ The accumulated data are contradictory. In principle in situ techniques are a promising solution to the problem unless too many different promoter species hamper interpretation.

An inconsistent picture evolves from literature and our data as to which preparation method favors incorporation. From our data, we would conclude that co-precipitation favors incorporation, which is supported by Miao's ${ }^{19}$ data and by Stöcker's ${ }^{37}$ as well as Okamoto's ${ }^{49}$ remarks. Tábora and Davis $^{3}$ though also used this method and claimed that there is no incorporation. Yamamoto et al. ${ }^{5}$ reported incorporation for Fe and not for $\mathrm{Mn}$, where our experience says that $\mathrm{Mn}$ should be incorporated more easily. In order to achieve more consistent information on these promoted catalysts, the preparative potential needs to be exhausted in that the promoters are added in a controlled manner.

\section{Summary}

The promoters $\mathrm{Fe}$ and $\mathrm{Mn}$ are in part incorporated into the zirconia lattice in promoted sulfated zirconia catalysts; incorporation was concluded from XRD, EPR, ISS, and XANES data, and from the comparison of these characterization data to those of a series of sulfate-free reference compounds with deliberately incorporated promoters (via coprecipitation). $\mathrm{Mn}$ and $\mathrm{Fe}$ gave rise to narrow, wellresolved EPR lines indicative of isolated species in a highly symmetric environment. $\mathrm{Mn}$ and Fe can be used as probes inside the zirconia lattice for better understanding of its bulk properties. In a typical catalyst containing about $2 \mathrm{wt} \%$ promoter metal, incorporated and surface promoter species may coexist.

At $2 \mathrm{wt} \%$ promoter content, ISS showed Fe at the surface but not $\mathrm{Mn}$, indicating a higher degree of incorporation of $\mathrm{Mn}$ for our catalyst preparations. The extra-lattice $\mathrm{Fe}$ formed an $\mathrm{Fe}_{2} \mathrm{O}_{3}$-like species that accounted for at least $50 \%$ of the $\mathrm{Fe}$ and could be removed by washing with oxalic acid as shown by XANES.

The incorporation leads to a stabilization of the tetragonal (or cubic) $\mathrm{ZrO}_{2}$ structure. The unit cell volume of the tetragonal phase shrank with increasing promoter content for the reference compounds and for Mn-promoted sulfated zirconia; there was no clear trend for Fe-promoted sulfated zirconia. It was not possible to correlate the catalytic performance with simple bulk structural information such as the unit cell parameters. The more or less complete incorporation of Mn suggests that embedded species in surface-near regions are responsible for the promotional effect. The lower valent promoter cations produce oxygen vacancies (defects) in the zirconia lattice; near the surface such defects are equivalent to surface cations with a high degree of unsaturation. In cooperation with sulfate groups such sites could be 
responsible for the high isomerization activity of promoted sulfated zirconia catalysts.

\section{Acknowledgments}

The authors would like to thank Sophia Klokishner for discussion of the EPR data, Edith Kitzelmann for assistance with the XRD measurements, and Edmund Welter and Konstantin Klementiev for their support at Hasylab beamline E4.

\section{References}

1 C.-Y. Hsu, C.R. Heimbuch, C.T. Armes, B.C. Gates, J. Chem. Soc., Chem. Comm. (1992) 1645-1646.

2 C. Morterra, G. Cerrato, S. Di Ciero, M. Signorotto, A. Minesso, F. Pinna, G. Strukul, Catal. Lett. 49 (1997) 25-34.

3 J.E. Tábora, R.J. Davis, J. Chem. Soc., Faraday Trans. 91,12 (1995) 1825-1833.

4 T. Tanaka, T. Yamamoto, Y. Kohno, T. Yoshida, S. Yoshida, Jpn. J. Appl. Phys. 38 (1999) 30-35.

5 T. Yamamoto, T. Tanaka, S. Takenaka, S. Yoshida, T. Onari, Y. Takahashi, T. Kosaka, S. Hasegawa, M. Kudo, J. Phys. Chem. B 103 (1999) 2385-2393.

6 W.E. Alvarez, H. Liu, D.E. Resasco, Appl. Catal. A: General 162 (1997) 103-119.

7 V. Adeeva, J.W. de Haan, J. Jänchen, G.D. Lei, V. Schünemann, L.J.M. van de Ven, W.M.H. Sachtler, R.A. van Santen, J. Catal. 151 (1995) 364-372.

8 V. Adeeva, G.D. Lei, W.M.H. Sachtler, Applied Catalysis A: General 118 (1994) L11-L15.

9 V. Adeeva, H.-Y. Liu, B.-Q. Xu, W.M.H. Sachtler, Topics in Catalysis 6 (1998) 61-76.

10 T.-K. Cheung, J.L. d'Itri, B.C. Gates, J. Catal. 151 (1995) 464-466.

11 A. Jatia, C. Chang, J.D. MacLeod, T. Okubo, M.E. Davis, Catal. Lett. 25 (1994) 21-28.

12 X. Song, K.R. Reddy, A. Sayari, J. Catal. 161 (1996) 206-210.

13 A. Sayari, Y. Yang, X. Song, J. Catal. 167 (1997) 346-353.

14 A. Sayari, Y. Yang, J. Catal. 187 (1999) 186-190.

15 R. Srinivasan, R.A. Keogh, A. Ghenciu, D. Fărcaşiu, B.H. Davis, J. Catal. 158 (1996) 502-510.

16 E.C. Sikabwe, M.A. Coelho, D.E. Resasco, R.L. White, Catal. Lett. 34 (1995) 23-30.

17 R. Srinivasan, R.A. Keogh, B.H. Davis, Appl. Catal. A: General 130 (1995) 135-155.

18 R.E. Jentoft, A. Hahn, F.C. Jentoft, T. Ressler, J. Synchrotron Rad. 8 (2001) 563-565.

19 C. Miao, W. Hua, J. Chen, Z. Gao, Catal. Lett. 37 (1996) 187-191.

20 C.-H. Lin, C.-Y. Hsu, J. Chem. Soc. Chem. Comm. (1992) 1479-1480.

21 D.R. Milburn, R.A. Keogh, D.E. Sparks, B.H. Davis, Appl. Surf. Sci. 126 (1998) 11-15.

22 S.X. Song, R.A. Kydd, Catal. Lett. 51 (1998) 95-100.

23 M. Scheithauer, E. Bosch, U.A. Schubert, H. Knözinger, F.C. Jentoft, B.C. Gates, B. Tesche, J. Catal. 177 (1998) $137-146$.

24 M.A. Coelho, D.E. Resasco, E.C. Sikabwe, R.L. White, Catal. Lett. 32 (1995) 253-262.

25 M.A. Coelho, W.E. Alvarez, E.C. Sikabwe, R.L. White, D.E. Resasco, Catal. Today 28 (1996) 415-429.

26 K.T. Wan, C.B. Khouw, M.E. Davis, J. Catal. 158 (1996) 311-326.

27 M. Benaissa, J.G. Santiesteban, G. Diaz, M. José-Yacaman, Surf. Sci. 364 (1996) L591-L594.

28 E.A. García, E.H. Rueda, A.J. Rouco, Appl. Catal. A: General 210 (2001) 363-370.

29 K. Arata, Appl. Catal. A: General 146 (1996) 3-32.

30 J.C. Yori, J.M. Parera, Appl. Catal. A: General 147 (1996) 145-157.

31 F.C. Lange, T.-K. Cheung, B.C. Gates, Catal. Lett. 41 (1996) 95-99.

32 E.C. Sikabwe, R.L. White, Catal. Lett. 44 (1997) 177-183.

33 S. Ardizzone, C.L. Bianchi, Surface and Interface Analysis 30 (2000) 77-80.

34 M. Hino, K. Arata, Catal. Lett. 34 (1996) 125-128.

35 J.M.M. Millet, M. Signoretto, P. Bonville, Catal. Lett. 64 (2000) 135-140.

36 E.A. García, E.H. Rueda, A.J. Rouco, Appl. Catal. A: General 210 (2001) 363-370.

37 H. J. Stöcker, Ann. Chim. 5 (1960) 1459-1502.

28 J. Stöcker, R. Collongues, Compt. Red. 245 (1957) 695-697.

39 A. Keshavaraja, A.V. Ramaswamy, J. Mater. Res. 9,4 (1994) 837-840.

40 A. Keshavaraja, N.E. Jacob, A.V. Ramaswamy, Thermochimica Acta 254 (1995) 267-275.

41 A. Keshavaraja, A.V. Ramaswamy, Appl. Catal. B: Environmental 8 (1996) L1-L7.

42 A. Keshavaraja, A.V. Ramaswamy, Chem. Comm. (1996) 397-398.

43 E. Fernández López, V. Sánchez Escribano, C. Resino, J.M. Gallardo-Amores, G. Busca, Appl. Catal. B: Environmental 29 (2001) $251-261$.

44 M. Valigi, D. Gazzoli, R. Dragone, A. Marucci, G. Mattei, J. Mater. Chem. 6,3 (1996) 403-408.

45 J.A. Navío, M.C. Hidalgo, G. Colón, S.G. Botta, M.I. Litter, Langmuir 17 (2001) 202-210.

46 L.A. Boot, A.J. van Dillen, J.W. Geus, F.R. Van Buren, J. Catal. 163 (1996) 186-194.

47 L.A. Boot, A.J. van Dillen, J.W. Geus, F.R. Van Buren, J. Catal. 163 (1996) 195-203.

48 Y. Okamoto, T. Kubota, Y. Ohto, S. Nasu, J. Catal. 192 (2000) 412-422.

49 Y. Okamoto, T. Kubota, Y. Ohto, S. Nasu, J. Phys. Chem. B 104 (2000) 8462-8470.

50 L.A. Boot, M.H.J.V. Kerkhoffs, B.Th. van der Linden, A.J. van Dillen, J.W. Geus, F.R. van Buren, Appl. Catal. A: General 137 (1996) $69-68$.

51 G. Bayer, J. Am. Ceram. Soc. 53,5 (1970) 294.

52 R. Srinivasan, D. Taulbee, B.H. Davis, Catal. Lett. 9 (1991) 1-8.

53 C. Morterra, G. Cerrato, F. Pinna, M. Signoretto, J. Catal. 157 (1995) 109-123. 
54 A. Hahn, T. Ressler, R.E. Jentoft, F.C. Jentoft, Chem. Commun. (2001) 537-538.

55 W. Kraus, G. Nolze, Federal Institute for Materials Research and Testing (BAM) Unter den Eichen 87, D-12205 Berlin. 56 J. Ilavsky, J.K. Stalick, Surface and Coatings Technology 127 (2000) 120-129.

57 D.N. Argyriou, C.J. Howard, J. Appl. Cryst. 28 (1995) 206-208.

58 J.A. Wang, M.A. Valenzuela, J. Salmones, A. Vásquez, A. García-Ruiz, X. Bokhimi, Catal. Today 68 (2001) 21-30.

59 R. Srinivasan, T.R. Watkins, C.R. Hubbard, B.H. Davis, Chem. Mater. 7 (1995) 725-730.

60 M. Li, Z. Feng, G. Xiong, P. Ying, Q. Xin, C. Li, J. Phys. Chem. B 105 (2001) 8108-8111.

61 B. Djuričić, S. Pickering, D. McGarry, P. Glaude, P. Tambuyser, K. Schuster, Ceram. Int. 21 (1995) 195-206.

62 L.N. Komissarova, Yu.P. Simanov, Z.A. Vladimirova, Russ. J. Inorg. Chem. 5,7 (1960) 687-689.

63 F.E. Mabbs, D. Collins, Electron paramagnetic resonance of d transition metal compounds, Elsevier, Amsterdam, 1992.

64 K. Dyrek, Z. Sojka, W. Zabinski, Mineral. Polon. 26 (1995) 9-16.

65 P. Li, I.-W. Chen, J.E. Penner-Hahn, Phys. Rev. B 48 (1993) 10063-10073.

66 M. Yashima, N. Ishizawa, M. Yoshimura, J. Am. Ceram. Soc. 75,6 (1992) 1550-1557.

67 P. Li, I.-W. Chen, J.E. Penner-Hahn, Phys. Rev. B 48 (1993) 10074-10081.

68 N. Ishizawa, Y. Matsushima, M. Hayashi, M. Ueki, Acta Cryst. B 55 (1999) 726-735.

69 R.D. Shannon, Acta Cryst. A 32 (1976) 751-767.

70 K. Sasaki, J. Maier, Solid State Ionics 134 (2000) 303-321.

71 H. Nishizawa, T. Tani, K. Matsuoka, J. Mater. Sci. 19 (1984) 2921-2926.

72 J. Luo, R. Stevens, J. Am. Ceram. Soc. 82 (1999) 1922-1924.

73 T. Ressler, S.L. Brock, J. Wong, S.L. Suib, J. Phys. Chem. 193 (1999) 6407-6420.

74 T.S. Jones, S. Kimura, A. Muan, J. Am Ceram. Soc. 50,3 (1967) 137-142.

75 D.E. Resasco, M.A. Coelho, E. Sikabwe, R.L. White, Poster presented at 14th NAM, Snowbird, Utah, June 11-16, 1995.

76 R. Ahmad, J. Melsheimer, F.C. Jentoft, R. Schlögl, J. Catal. 218 (2003) 365-374.

77 S. Kuba, B.C. Gates, R.K. Grasselli, H. Knözinger, Chem. Commun. (2001) 321-322.

78 K. Arata, H. Matsuhashi, M. Hino, H. Nakamura, Catal. Today 81 (2003) 17-30.

79 W. Stichert, F. Schüth, J. Catal. 174 (1998) 242-245.

80 A. Hahn, R.E. Jentoft, T. Ressler, F.C. Jentoft, in preparation.

81 R.E. Jentoft, A. Hahn, F.C. Jentoft, T. Ressler, in preparation.

82 R.E. Jentoft, A. Hahn, F.C. Jentoft, T. Ressler, Physica Scripta, in press. 